\title{
A practical solution to improve the nutritional balance of Korean dine-out menus using linear programming
}

\author{
Jang Ho Kim ${ }^{1}$, Woo Chang $\mathrm{Kim}^{2}$ and Jihye Kim ${ }^{3, *}$ \\ ${ }^{1}$ Industrial and Systems Management Engineering, Kyung Hee University, Gyeonggi-do, Republic of Korea: \\ ${ }^{2}$ Industrial and Systems Engineering, KAIST, Daejeon, Republic of Korea: ${ }^{3}$ Department of Medical Nutrition, \\ Graduate School of East-West Medical Science, Kyung Hee University, 1732 Deogyeong-daero, Giheung-gu, \\ Yongin-si, Gyeonggi-do 17104, Republic of Korea
}

Submitted 11 July 2018: Final revision received 2 November 2018: Accepted 7 December 2018: First published online 15 February 2019

\begin{abstract}
Objective: We analysed optimal nutrient levels using linear programming (LP) to reveal nutritional shortcomings of Korean dine-out meals and to stress the importance of fruits and dairy products for maintaining a healthy diet.

Design: LP models that minimize deviation from recommended nutrient values were formulated to analyse deficiency or excess of nutrients under the best situation.

Setting: Korean dine-out menus and nutritional information were taken from the nutrient composition tables for dine-out menus developed by the Ministry of Food and Drug Safety and the nutrient database from Computerized Analysis Program. Acceptable macronutrient distribution ranges of macronutrients such as carbohydrate, protein and fat, and recommended intake levels for energy, vitamins, minerals and cholesterol, by sex, were based on the Dietary Reference Intake for Koreans aged 30-49 years.

Participants: Optimization was performed on selecting the optimal Korean meal combination.

Results: LP optimization models showed that it is unlikely to satisfy all nutrient recommendations with any combination of dine-out menus. Specifically, meal combinations of Korean dine-out menus had high levels of $\mathrm{Na}$ and cholesterol and low levels of vitamins and minerals. Four formulations were considered to compare the effects of controlling $\mathrm{Na}$ and including fruit and dairy products. The unbalanced diet was resolved with extra consumption of fruits and dairy products. Conclusions: The best meal combination in dine-out menus, even though the proportion and pairing of menus may be unrealistic, is not healthy, and thus one should consume fruits and dairy products to maintain a balanced diet.
\end{abstract}

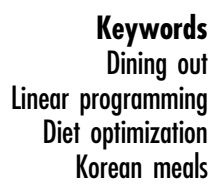

Demographic changes are affecting our meal patterns such as when we eat, where we eat and who we eat with ${ }^{(1,2)}$. Even though a healthy diet is an important aspect of a healthy life, maintaining a healthy diet is not an easy task in today's society. An increase in dual-income households and long work hours are attracting individuals and families to dine out, take out or order in from restaurants $^{(3)}$. Likewise, the proportion of one-person households and dual-income households is expanding and an increasing number of individuals are enjoying eating out rather than cooking their own meals in South Korea ${ }^{(4)}$. While the variety of menus and convenience of eating out or ordering in have been improving, it is still generally difficult to maintain a well-balanced diet from available restaurant menus.
In fact, dining out alone has become popular in recent years, especially among the younger generation, and many restaurants nowadays have customized menus and special seating for customers who come alone ${ }^{(5)}$. Moreover, delivery service for restaurants has improved significantly; some companies specialize in delivering takeout meals where individuals can order food from any restaurant and even have meals delivered to an outdoor location such as a public park ${ }^{(6)}$.

The popularity in eating out is due to its convenience, mainly because it is the best option for saving time. However, the general guideline is to avoid dining out frequently because it is difficult to consume all the necessary nutrients that are recommended for a healthy diet. 
The dine-out culture of Korea is unique because Korean restaurants do not serve full-course meals and most restaurants that serve main dishes do not offer dessert. A main menu is usually served with several side menus, but dessert menus are often skipped because they cannot be consumed in one seating. While Korean meals use various grains, meats and vegetables, it is very rare for fruit and dairy products to be used as ingredients. Hence, a critical concern with the Korean dine-out culture is the shortage of fruit and dairy products that results in imbalance of nutritional intake.

Several studies have reported dine-out patterns and nutritional adequacy or health outcomes. A systematic review described that eating out of home was associated with a higher total energy intake and energy contribution from fat in the daily diet, as well as with a lower intake of micronutrients, particularly vitamin $\mathrm{C}, \mathrm{Ca}$ and $\mathrm{Fe}^{(7)}$. Watts et al. have shown that more frequent dinner meals prepared away from home and eating out with friends were associated with lower scores on the Healthy Eating Index adapted to the Canadian context among adolescents with overweight or obesity ${ }^{(8)}$. Korean dine-out meals are known to be high in $\mathrm{Na}$ and low in vitamins and minerals ${ }^{(9)}$. National survey data showed that individuals in the non-homemade meal group had higher energy intakes, with higher percentages of energy from protein and fat and lower intakes of dietary fibre, $\mathrm{P}, \mathrm{K}$, niacin and vitamin $\mathrm{C}$, than those in the homemade meal group among Korean adults ${ }^{(10)}$. Dining out on a regular basis might have longterm effects on one's health if one is not carefully selecting what to eat each day.

Therefore, the present study was conducted to discuss the nutritional shortcomings in Korean dine-out menus using linear programming (LP) and to suggest solutions to meet the recommended nutritional intake for people who habitually dine out using optimization models. Additionally, the study examined the possibility of application of LP as an approach for selecting a healthy diet plan.

\section{Methods}

\section{Database for dine-out menu extraction}

Korean dine-out menus and the nutritional information were taken from the nutrient composition tables for dineout menus developed by the Ministry of Food and Drug Safety ${ }^{(11-14)}$ and the nutrient database from Computerized Analysis Program (CanPro 5.0) ${ }^{(15)}$. Acceptable macronutrient distribution ranges of macronutrients such as carbohydrate, protein and fat, and recommended intake levels for energy, vitamins, minerals and cholesterol, by sex, were based on the Dietary Reference Intake for Koreans ${ }^{(16)}$. We focused our analysis to the age group from 30 to 49 years.

The distribution of dine-out menus used in the analysis is summarized in Fig. 1, where a total of 331 menus are included. Most menus categorized as rice, noodle or soup (with rice) are generally served as the main dish and other foods are often served together as side dishes. Since the number and type of side dishes depend mostly on the restaurant and not the menu ordered, it is common to eat from many menus on the list for a single meal. Fruit and dairy products are normally not included in Korean dineout menus, but the nutrition data are used in our analysis as discussed further in the 'Menu optimization: additional model' subsection below.

\section{Menu optimization: formulation}

We first present the formulation of the mathematical program used in the present study in this subsection and then include intuitive descriptions of various models that were analysed in the next two subsections. It should be noted that the proposed formulation does not find a dine-out menu combination relative to another plan (i.e. improve an existing plan) and, thus, the solution is the absolute optimal decision that provides the best possible nutrient combination. The dine-out menu optimization problem can be formally expressed as:

$$
\begin{aligned}
\text { Minimize } & \frac{\sum_{i \in L} \max \left(l_{i}-x_{i}, 0\right)+\sum_{i \in U} \max \left(x_{i}-u_{i}, 0\right)}{N} \\
\text { Subject to } & l_{\text {cal }} \leq x_{\text {cal }} \leq u_{\text {cal }} \\
& 0 \leq w_{j} \leq 1 \text { for each menu } j \\
& x_{i}=\sum_{j} n_{i, j} w_{j} \text { for each nutrient } i
\end{aligned}
$$

where the decision variable $x_{i}$ represents the total consumption level of the $i$ th nutrient and $w_{j}$ represents the consumption of the $j$ th menu expressed as a proportion of a single serving. The sets $L$ and $U$ represent nutrients that have recommended lower and upper levels, respectively. Furthermore, the constant $l_{i}$ represents lower limits for nutrients in $L$, and $u_{i}$ represents upper recommended levels for nutrients in $U$. Since bounds on total energy (calories) are included as a strict restriction, $x_{c a l}$ is constrained to be within $l_{c a l}$ and $u_{c a l}$. Finally, $n_{i, j}$ represents the amount of the $i$ th nutrient that can be consumed from eating the $j$ th menu. The objective value computes the average deviation by dividing the total deviation by $N$, which is the number of nutrients optimized.

The optimization problem given by equation (1) can also be written as below without the maximization in the objective function as:

$$
\operatorname{Minimize} \frac{\sum_{i \in L} \frac{d_{i}}{l_{i}}+\sum_{i \in U} \frac{e_{i}}{u_{i}}}{N}
$$

$$
\begin{array}{ll}
\text { Subject to } & l_{c a l} \leq x_{c a l} \leq u_{c a l} \\
& 0 \leq w_{j} \leq 1 \text { for each menu } j \\
& x_{i}=\sum_{j} n_{i, j} w_{j} \text { for each nutrient } i \\
& y_{i}=x_{i}-e_{i}+d_{i} \text { for each nutrient } i \\
& y_{i} \leq u_{i} \text { for } i \in U
\end{array}
$$




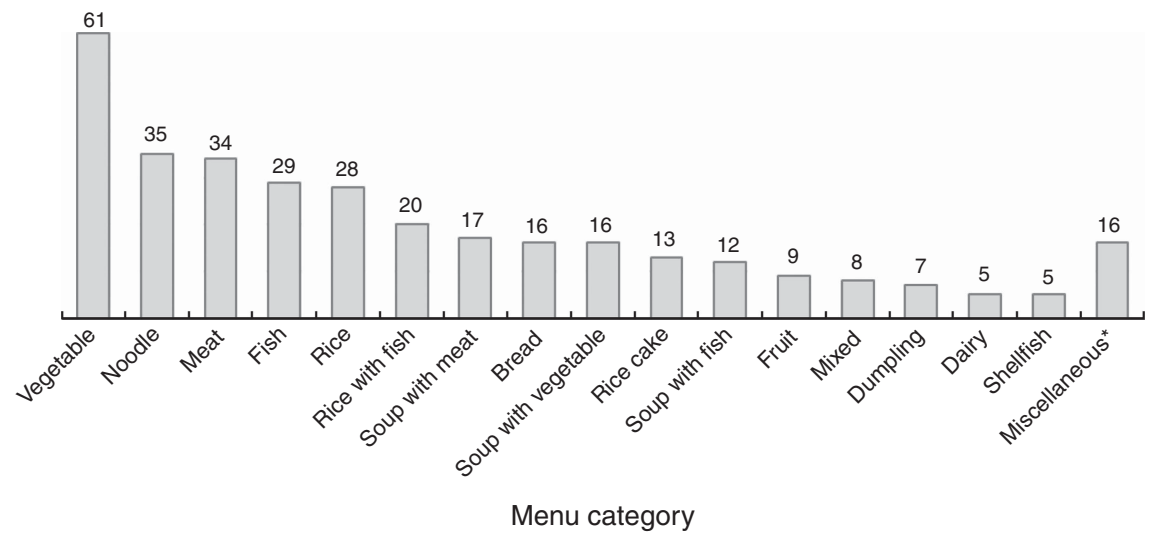

Fig. 1 Summary of Korean dine-out menu data ${ }^{(11-14)}$, showing the number of menus analysed by category (total, $n$ 331). *Miscellaneous includes legume, soup with legume, rice with meat, rice with vegetable, grain, egg, and soup with egg

$y_{i} \geq l_{i}$ for $i \in L$

$e_{i} \geq 0, d_{i} \geq 0$ for all $i$

where slack variables $e_{i}$ and $d_{i}$ represent the excessive consumption and the deficient amount of the $i$ th nutrient, respectively. The use of slack variables and additional dummy variables $y_{i}$ formulates the original problem (1) into a problem (2) that is more solver-friendly. Solving the optimization problem (1) or (2) provides the optimal choice of dine-out menu that satisfies all constraints while minimizing the proportion of nutrients that do not fall within guidelines.

\section{Menu optimization: base model}

In our analysis, we formulated the dine-out menu optimization problem as below for finding a complete diet that attempts to satisfy recommended daily nutrition levels.* We refer to this formulation as Case A.

$\begin{array}{cc}\begin{array}{c}\text { Case A } \\ \text { Decision } \\ \text { variables: }\end{array} & \begin{array}{c}\text { Base model } \\ \text { Amount of each menu to consume } \\ \text { (expressed as a proportion of a } \\ \text { single serving) }\end{array} \\ \text { Objective } & \begin{array}{c}\text { Minimize deviation from } \\ \text { recommended level for each } \\ \text { function: }\end{array} \\ & \text { nutrient }\end{array}$

Constraint 1: Total daily energy consumption must be within recommended range

Constraint 2: Each menu can only be consumed up to a single serving

There is one decision variable for every dine-out menu considered in the problem. If a menu is not chosen, the corresponding decision variable will have a value of 0 . If a decision variable has a value of 0.5 , it shows that half a serving of the corresponding menu should be consumed.

* The basic components of optimization problems are further discussed in the 'Optimization models' subsection.
As shown above, in Case A the objective function is to minimize deviation from the recommended nutrition levels. Since some nutrients have recommended lower bounds while others have suggested upper bounds, the objective function measures deficiency of nutrients with lower bounds and excess of nutrients with upper bounds. Furthermore, since the recommended levels are different for different nutrients, we measured the percentage of deficiency or excess instead of the actual value.

Energy consumption is most critical for maintaining one's health. It is known that energy restriction improves metabolic efficiency and reduces oxidative damage markers, which may decrease incidence and progression of chronic diseases such as obesity, metabolic syndrome and cancer $^{(17)}$. Therefore, the first constraint of the menu optimization problem in Case A forces total daily energy to be within a recommended range. This constraint makes sure one consumes at least the minimum energy necessary for an average lifestyle and also avoids consuming too much food that will eventually lead to weight gain and reduced health conditions. The second constraint limits the consumption of each dine-out menu to a maximum of 1 serving/d and this reflects the unlikelihood of eating the same menu more than once on the same day. Together with the definition of the decision variables, each menu will have a value between 0 and 1 .

The recommended nutrition levels are summarized in Table 1. We focused the analysis on nutritional recommendations for ages 30-49 years because this is the age group with the most frequent dineouts in South Korea. The limits for energy are used in the first constraint and the other suggested levels are used for computing the objective function value.

\section{Menu optimization: additional model}

In addition to the base model given by Case A, we compared a few variations to analyse how changes in allowed 
Table 1 Lower and upper limits and recommended level of daily nutrient intakes for Korean adults aged $30-49$ years, by sex ${ }^{(16)}$

\begin{tabular}{|c|c|c|c|c|c|c|}
\hline \multirow[b]{2}{*}{ Nutrient } & \multicolumn{3}{|c|}{ Males } & \multicolumn{3}{|c|}{ Females } \\
\hline & $\begin{array}{l}\text { Lower } \\
\text { limit }\end{array}$ & $\begin{array}{l}\text { Upper } \\
\text { limit }\end{array}$ & $\begin{array}{l}\text { Recommended intake } \\
\text { level }\end{array}$ & $\begin{array}{l}\text { Lower } \\
\text { limit }\end{array}$ & $\begin{array}{l}\text { Upper } \\
\text { limit }\end{array}$ & $\begin{array}{l}\text { Recommended intake } \\
\text { level }\end{array}$ \\
\hline Energy (kJ; strict lower/upper limits) & 9832 & 10251 & 10042 & 7740 & 8159 & 7950 \\
\hline $\begin{array}{l}\text { Energy (kcal; strict lower/upper } \\
\text { limits) }\end{array}$ & 2350 & 2450 & 2400 & 1850 & 1950 & 1900 \\
\hline Carbohydrate $(\mathrm{g})$ & - & 398 & $55-65 \% \mathrm{E}$ & - & 317 & $55-65 \% \mathrm{E}$ \\
\hline Protein $(g)$ & - & 123 & $7-20 \% E$ & - & 98 & $7-20 \% E$ \\
\hline Total fat $(\mathrm{g})$ & - & 82 & $15-30 \% \mathrm{E}$ & - & 65 & $15-30 \% \mathrm{E}$ \\
\hline Thiamin (mg) & 1.2 & - & 1.2 & $1 \cdot 1$ & - & $1 \cdot 1$ \\
\hline Riboflavin (mg) & 1.5 & - & 1.5 & $1 \cdot 2$ & - & $1 \cdot 2$ \\
\hline Vitamin C (mg) & 100 & - & 100 & 100 & - & 100 \\
\hline Niacin (mg) & 16 & - & 16 & 14 & - & 14 \\
\hline Folate (mg) & 0.4 & - & 0.4 & 0.4 & - & 0.4 \\
\hline Cholesterol (mg) & - & 300 & 300 & - & 300 & 300 \\
\hline $\mathrm{Na}(\mathrm{mg})$ & - & 2000 & 2000 & - & 2000 & 2000 \\
\hline $\mathrm{K}(\mathrm{mg})$ & 3500 & - & 3500 & 3500 & - & 3500 \\
\hline $\mathrm{Ca}(\mathrm{mg})$ & 800 & - & 800 & 700 & - & 700 \\
\hline $\mathrm{Fe}(\mathrm{mg})$ & 10 & - & 10 & 14 & - & 14 \\
\hline$P(\mathrm{mg})$ & 700 & - & 700 & 700 & - & 700 \\
\hline $\mathrm{Mg}(\mathrm{mg})$ & 370 & - & 370 & 280 & - & 280 \\
\hline $\mathrm{Mn}(\mathrm{mg})$ & 4 & - & 4 & 3.5 & - & 3.5 \\
\hline Se (mg) & 60 & - & 60 & 60 & - & 60 \\
\hline $\mathrm{Cu}(\mathrm{mg})$ & 800 & - & 800 & 800 & - & 800 \\
\hline $\mathrm{Zn}(\mathrm{mg})$ & 10 & - & 10 & 8 & - & 8 \\
\hline
\end{tabular}

$\% \mathrm{E}$, percentage of energy.

menu choices and constraints affect the optimal decision. The four cases are summarized below.

Case A Base model

Case B Case A + upper bound constraint on total $\mathrm{Na}$ consumption

Case C Case B + fruit and dairy products added to menu data

Case D Case C + constraints to limit total fruit consumption between 100 and $300 \%$ and total dairy product consumption between 100 and $200 \%$

The first case is the base model introduced in the previous subsection. As shown in the 'Results' section, the base case revealed significant overconsumption of $\mathrm{Na}$, which is a widely known concern in Korean meals ${ }^{(4)}$. Thus, the second case, referred to as Case B, added a strict upper limit on total $\mathrm{Na}$ consumption. This second case will demonstrate how the optimal menus change when one is forced not to exceed the Na limit when excess use of salt is common in Korean meals. Case C solved the same optimization model as Case $\mathrm{B}$, but it selected from more menus. More specifically, Case $\mathrm{C}$ will find the optimal diet when fruit and dairy products are included as shown in Table 2. This third case is important because fruit and dairy products are difficult to find in dine-out menus even though they are excellent choices for intake of vitamins and minerals. Finally, Case D restricted the total selection of fruits and dairy products to be at least 1 serving/d but less than 2 or 3 servings/d. The upper limit of 3 servings/d (300\%) for fruit and 2 servings/d (200\%) for dairy products reflects the recommended daily amount for adults aged 30-49 years whose recommended energy level is $10042 \mathrm{~kJ} / \mathrm{d}(2400 \mathrm{kcal} / \mathrm{d})^{(16)}$. This last constraint portrays a more realistic situation since people usually do not eat excess amounts of fruit or dairy products, especially when one eats out regularly. In Cases C and D we included only fruit and dairy products but no other food groups such as grains or vegetables because, while most food groups including vegetables are commonly used as ingredients of Korean dine-out menus, fruit and dairy products cannot be consumed unless eaten separately (e.g. as dessert).

Although the Cases B, C and D are variations of the base model (Case A), the additional cases do not change the overall structure of the optimization problem because the extra constraints are all expressed as linear functions. In the 'Results' section, results of the four models are compared to analyse optimal dine-out decisions under various conditions.

\section{Optimization models}

The menu optimization problems presented above allow the selection of any single menu in any proportion between 0 and 1; 0 represents not selecting the menu and 1 represents selecting one serving of the menu. Nevertheless, since fractions are also possible, it is possible to select, for example, half a serving $(0.5)$ or a tenth of a serving $(0 \cdot 1)$. 
Table 2 List of fruit and dairy products included in menu data

\begin{tabular}{|c|c|c|c|c|c|c|}
\hline & Serving size $(\mathrm{g})$ & Energy (kJ) & Energy (kcal) & Carbohydrate (g) & Protein $(\mathrm{g})$ & Total fat $(\mathrm{g})$ \\
\hline \multicolumn{7}{|l|}{ Dairy products } \\
\hline Milk & 200 & 502 & 120 & 9.4 & $6 \cdot 4$ & $6 \cdot 4$ \\
\hline Low-fat milk & 200 & 301 & 72 & $9 \cdot 2$ & 5.8 & 1.2 \\
\hline Coffee milk & 200 & 527 & 126 & 21.0 & 5.4 & $2 \cdot 4$ \\
\hline Yoghurt & 100 & 431 & 103 & $16 \cdot 8$ & 3.5 & $2 \cdot 4$ \\
\hline Ice cream & 100 & 607 & 145 & $22 \cdot 7$ & 3.8 & $4 \cdot 3$ \\
\hline \multicolumn{7}{|l|}{ Fruit } \\
\hline Banana & 100 & 335 & 80 & $21 \cdot 2$ & 1.0 & 0.0 \\
\hline Tangerine & 100 & 167 & 40 & $10 \cdot 5$ & 0.5 & 0.1 \\
\hline Orange & 100 & 184 & 44 & $11 \cdot 2$ & 0.9 & $0 \cdot 1$ \\
\hline Grape & 100 & 251 & 60 & $14 \cdot 1$ & 0.4 & 0.8 \\
\hline Strawberry & 200 & 243 & 58 & 14.4 & 1.6 & 0.2 \\
\hline Kiwi & 100 & 268 & 64 & $14 \cdot 8$ & 0.8 & 1.0 \\
\hline Peach & 100 & 201 & 48 & $10 \cdot 0$ & 1.8 & 0.7 \\
\hline Watermelon & 200 & 268 & 64 & $16 \cdot 2$ & 1.6 & 0.0 \\
\hline Apple & 100 & 205 & 49 & $13 \cdot 1$ & 0.2 & 0.1 \\
\hline
\end{tabular}

The model is purposely designed this way because we are interested in observing the healthiest choice of dineout menus under a situation that is not too restrictive. If a healthy diet is not possible under a non-restrictive condition, it will certainly be impossible under more restrictions. Limiting selections to be only either zero or one serving, or a choice among a few portions (e.g. quarter, half or full serving), becomes a more restrictive model.

\section{Linear programming for nutrient analysis}

Optimization methods compute the optimal solution under specified conditions and LP (or linear optimization) is the simplest form of optimization problems where the problem settings are described by linear functions ${ }^{(18,19)}$. More specifically, LP finds the best solution for achieving the decision maker's objective, where the objective function could be to either maximize or minimize.

There have been studies that employ LP methods for analysing nutrients and recommending diet guidelines. One of the most popular approaches for utilizing linear optimization is to find a healthy diet (or food combination) that satisfies given nutrient recommendations but requires minimum change from the current diet pattern ${ }^{(20-22)}$.

In contrast to previous studies, we introduce a new formulation that finds the optimal dine-out menu combination without reference to any previous pattern. Since the formulation in our analysis is expressed as a linear program, the solution is the absolute optimal decision that provides the true optimum and best possible nutrient combination.

\section{Results}

Findings from the four cases were compared and we begin by discussing results for males before mentioning those for females. The results from our optimization analyses are presented by gender in Tables 3-8.*

\section{Males}

First, Case (A), which is the base case that restricts only total energy consumption and the amount of serving per menu, could not satisfy all recommended nutrient levels and even the optimal choice showed 3.03\% average deviation from recommendation. The most noticeable issue is a $56 \%$ excess in $\mathrm{Na}$. This shows that the optimal combination of dine out-menus can satisfy the guideline levels of most nutrients except for $\mathrm{Na}$ (deficiency in $\mathrm{K}$ is only about $1 \%$ ). In other words, it will be possible to find a healthy menu combination if Korean meals contained less $\mathrm{Na}$. This observation on Case A confirms, through optimization, that the main concern in Korean meals is the excessive amount of Na (Table 3).

When the level of $\mathrm{Na}$ is restricted to a maximum of $2000 \mathrm{mg}$ in Case B, the optimal decision became worse with an increased average deviation of $5 \cdot 84 \%$. Even though no nutrients had excessive levels, minerals such as niacin, folate, $\mathrm{K}$ and $\mathrm{Mg}$ could not reach their recommended minimum levels of consumption. This illustrates that simply limiting the consumption of $\mathrm{Na}$ is not the solution to reaching a balanced diet (Table 3).

Cases $\mathrm{C}$ and $\mathrm{D}$, that add fruits and dairy products to the list of candidate menus, support how additional sources of vitamins and minerals are critical. Case C clearly showed the most efficient selection with less than $1 \%$ average deviation and only $\mathrm{Mg}$ being below recommended levels. Moreover, Case $\mathrm{D}$, which is a more realistic situation, formed a meal plan that is more ideal than Cases $\mathrm{A}$ and $\mathrm{B}$. In comparison to Case B, Case $\mathrm{D}$ reduced the deficiency levels of folate, $\mathrm{K}$ and $\mathrm{Mg}$, and satisfied the recommended level for niacin (Table 3).

\footnotetext{
* Results presented were optimized using OpenSolver, which is an Excel add-in that uses COIN-OR branch-and-cut solver (CBC) for solving optimization problems
} 
Table 3 Results on optimal nutrition levels for Korean males aged 30-49 years from the dine-out menu optimization

\begin{tabular}{lcll}
\hline & $\begin{array}{c}\text { Average deviation from } \\
\text { recommended levels (\%) }\end{array}$ & Excessive nutrients (\%) & Deficient nutrients (\%) \\
\hline Case A & 3.03 & $\mathrm{Na}(+56 \cdot 3)$ & $\mathrm{K}(-1 \cdot 2)$ \\
Case B & 5.84 & None & Niacin $(-22 \cdot 1)$ \\
& & & Folate $(-15 \cdot 5)$ \\
& & & $\mathrm{K}(-45 \cdot 9)$ \\
Case C & 0.77 & None & $\mathrm{Mg}(-27 \cdot 6)$ \\
Case D & 2.05 & None & $\mathrm{Mg}(-14 \cdot 6)$ \\
& & & $\mathrm{Kolate}(-1 \cdot 6)$ \\
& & & $\mathrm{Mg}(-27 \cdot 5)$ \\
\hline
\end{tabular}

Table 4 List of menus selected by dine-out menu optimization in Case D for Korean males aged 30-49 years (sorted by decreasing optimal amount)

\begin{tabular}{|c|c|c|c|c|c|c|c|c|}
\hline Menu & Food group & $\begin{array}{l}\text { Optimal amount } \\
(\%)\end{array}$ & $\begin{array}{l}\text { Serving size } \\
\text { (g) }\end{array}$ & $\begin{array}{l}\text { Energy } \\
(\mathrm{kJ})\end{array}$ & $\begin{array}{l}\text { Energy } \\
\text { (kcal) }\end{array}$ & $\begin{array}{l}\text { Carbohydrate } \\
\text { (g) }\end{array}$ & $\begin{array}{l}\text { Protein } \\
\text { (g) }\end{array}$ & $\begin{array}{l}\text { Total fat } \\
\text { (g) }\end{array}$ \\
\hline $\begin{array}{l}\text { Fried sweet potato with syrup } \\
\text { (mat-tang) }\end{array}$ & Grain & 100 & $200 \cdot 00$ & $2054 \cdot 34$ & 491.00 & 94.60 & 3.30 & 11.00 \\
\hline Yoghurt & Dairy & 100 & $100 \cdot 00$ & $430 \cdot 95$ & $103 \cdot 00$ & $16 \cdot 80$ & 3.50 & 2.40 \\
\hline Grape & Fruit & 100 & $100 \cdot 00$ & 251.04 & 60.00 & $14 \cdot 10$ & 0.40 & 0.80 \\
\hline Peach & Fruit & 100 & $100 \cdot 00$ & $200 \cdot 83$ & 48.00 & $10 \cdot 00$ & 1.80 & 0.70 \\
\hline Starch jelly (acorn muk) & $\begin{array}{l}\text { Grain, } \\
\text { vegetables }\end{array}$ & 100 & $100 \cdot 00$ & $192 \cdot 46$ & 46.00 & $10 \cdot 40$ & 0.30 & 0.30 \\
\hline Milk & Dairy & 99 & $197 \cdot 31$ & $495 \cdot 30$ & $118 \cdot 38$ & $9 \cdot 27$ & $6 \cdot 31$ & $6 \cdot 31$ \\
\hline Beef cutlet & Meat & 79 & 158.23 & 2965.60 & 493.69 & 30.46 & $26 \cdot 11$ & 29.67 \\
\hline Watermelon & Fruit & 74 & $148 \cdot 34$ & 198.61 & 47.47 & $12 \cdot 02$ & $1 \cdot 19$ & 0.00 \\
\hline Rice with curry & Rice & 67 & 333.65 & $1876 \cdot 23$ & 448.43 & 84.08 & 9.01 & 8.47 \\
\hline Stir-fried dried shrimp & $\begin{array}{l}\text { Fish, } \\
\quad \text { vegetables }\end{array}$ & 53 & $10 \cdot 69$ & $147 \cdot 57$ & $35 \cdot 27$ & 3.05 & $2 \cdot 51$ & 1.44 \\
\hline Potato fries & Grain & 42 & $62 \cdot 71$ & 804.67 & $192 \cdot 32$ & 23.58 & $2 \cdot 30$ & 9.87 \\
\hline Strawberry & Fruit & 26 & 51.66 & 62.68 & 14.98 & 3.72 & 0.41 & 0.05 \\
\hline White rice & Rice & 25 & 22.56 & $333 \cdot 21$ & $79 \cdot 64$ & $17 \cdot 71$ & 1.29 & 0.02 \\
\hline Ox bone soup (with rice) & Meat & 20 & 162.00 & $617 \cdot 31$ & 147.54 & 16.65 & 12.95 & 2.94 \\
\hline Roasted pork ribs & Meat & 13 & 44.44 & 499.86 & $119 \cdot 47$ & 3.69 & $9 \cdot 23$ & 7.54 \\
\hline Low-fat milk & Dairy & 1 & 2.69 & 4.06 & 0.97 & 0.12 & 0.08 & 0.02 \\
\hline Oyster rice soup & $\begin{array}{l}\text { Grain, } \\
\text { shellfish }\end{array}$ & 0.5 & $3 \cdot 15$ & 13.85 & $3 \cdot 31$ & 0.43 & 0.21 & 0.09 \\
\hline Boiled pork & Meat & 0.04 & 0.13 & $2 \cdot 16$ & 0.52 & 0.00 & 0.03 & 0.04 \\
\hline Total & - & 999.4 & $1797 \cdot 57$ & $10205 \cdot 80$ & $2450 \cdot 00$ & 350.69 & 80.92 & 81.67 \\
\hline
\end{tabular}

The optimal menu combination for Case D is presented in Tables 4 and 5. The optimal meal for one day included portions of beef cutlet with rice, rice with curry, and ox bone soup with rice as main dishes, with several sides including sweet potatoes, starch jelly and stir-fried dried shrimps. More importantly, the meal showed that it is optimal to meet the recommended levels of fruit and dairy product consumption (3 servings/d for fruit and 2 servings/d for dairy products) through yoghurt, milk and some fruits. Our observations stress that one should not restrict one's diet to dine-out menus and should consciously add fruits and dairy products to his/her diet.

\section{Females}

The results for females, as shown in Table 6, were consistent with our findings for males above. Case A, the base case, again exhibited very high levels of $\mathrm{Na}$ and slight deficiency in a few minerals. When $\mathrm{Na}$ was controlled to not exceed the maximum allowed amount, the degree of deficiency in minerals increased and the average deviation from recommendations also rose. More importantly, adding fruits and dairy products found a perfect meal plan with no excessive or deficient nutrients. Even Case D, which limited the maximum consumption of fruits and dairy products, showed minimal insufficiency. Overall, the cases for females displayed a healthier diet in each case, but the key issues with dine-out menus were consistently observed. The list of menus selected for Case D are presented in Tables 7 and 8.

\section{Discussion}

The results of the present nutrient analysis for dine-out menus in Korea demonstrated issues in dining out and the 
Table 5 Food categories selected by dine-out menu optimization in Case D for Korean males aged 30-49 years

\begin{tabular}{|c|c|c|c|c|c|c|c|}
\hline Food group & Optimal amount (\%) & Serving size $(\mathrm{g})$ & Energy $(\mathrm{kJ})$ & Energy (kcal) & Carbohydrate (g) & Protein $(\mathrm{g})$ & Total fat $(\mathrm{g})$ \\
\hline Grain & 283.9 & $670 \cdot 50$ & 5171.63 & 1236.05 & $225 \cdot 39$ & $16 \cdot 15$ & 29.56 \\
\hline Meat, fish, shellfish & 138.8 & $371 \cdot 72$ & $3265 \cdot 65$ & $780 \cdot 51$ & 52.55 & 49.67 & $40 \cdot 96$ \\
\hline Vegetables & $76 \cdot 7$ & 55.34 & 170.00 & $40 \cdot 63$ & 6.72 & 1.41 & 0.87 \\
\hline Fruit & $300 \cdot 0$ & $400 \cdot 00$ & $713 \cdot 16$ & $170 \cdot 45$ & 39.84 & 3.80 & 1.55 \\
\hline Dairy & $200 \cdot 0$ & $300 \cdot 00$ & $930 \cdot 31$ & $222 \cdot 35$ & $26 \cdot 20$ & 9.89 & 8.73 \\
\hline Total & 999.4 & 1797.57 & $10250 \cdot 80$ & $2450 \cdot 00$ & $350 \cdot 69$ & 80.92 & 81.67 \\
\hline
\end{tabular}

Table 6 Results on optimal nutrition levels for Korean females aged 30-49 years from the dine-out menu optimization

\begin{tabular}{lcll}
\hline & $\begin{array}{c}\text { Average deviation from } \\
\text { recommended levels (\%) }\end{array}$ & Excessive nutrients (\%) & Deficient nutrients (\%) \\
\hline Case A & 2.72 & $\mathrm{Na}(+42 \cdot 5)$ & $\begin{array}{l}\text { Folate }(-1 \cdot 8) \\
\mathrm{K}(-7 \cdot 3)\end{array}$ \\
Case B & 3.88 & None & $\begin{array}{l}\text { Folate }(-20 \cdot 3) \\
\mathrm{K}(-41 \cdot 5)\end{array}$ \\
& & & $\mathrm{Mg}(-11 \cdot 9)$ \\
Case C & 0.00 & None & None \\
Case D & 0.74 & None & $\mathrm{K}(-14 \cdot 1)$ \\
\hline
\end{tabular}

Table 7 List of menus selected by dine-out menu optimization in Case D for Korean females aged 30-49 years (sorted by decreasing optimal amount)

\begin{tabular}{|c|c|c|c|c|c|c|c|c|}
\hline Menu & Food group & $\begin{array}{l}\text { Optimal amount } \\
(\%)\end{array}$ & $\begin{array}{l}\text { Serving size } \\
(\mathrm{g})\end{array}$ & $\begin{array}{l}\text { Energy } \\
(\mathrm{kJ})\end{array}$ & $\begin{array}{l}\text { Energy } \\
\text { (kcal) }\end{array}$ & $\begin{array}{l}\text { Carbohydrate } \\
\text { (g) }\end{array}$ & $\begin{array}{l}\text { Protein } \\
\text { (g) }\end{array}$ & $\begin{array}{l}\text { Total fat } \\
\text { (g) }\end{array}$ \\
\hline $\begin{array}{l}\text { Fried sweet potato with syrup } \\
\text { (mat-tang) }\end{array}$ & Grain & $100 \cdot 0$ & $200 \cdot 00$ & $2054 \cdot 34$ & 491.00 & 94.60 & $3 \cdot 30$ & 11.00 \\
\hline Grape & Fruit & $100 \cdot 0$ & $100 \cdot 00$ & 251.04 & $60 \cdot 00$ & $14 \cdot 10$ & 0.40 & 0.80 \\
\hline Peach & Fruit & $100 \cdot 0$ & $100 \cdot 00$ & $200 \cdot 83$ & 48.00 & $10 \cdot 00$ & 1.80 & 0.70 \\
\hline Starch jelly (acorn muk) & $\begin{array}{l}\text { Grain, } \\
\text { vegetables }\end{array}$ & $100 \cdot 0$ & $100 \cdot 00$ & $192 \cdot 46$ & $46 \cdot 00$ & $10 \cdot 40$ & 0.30 & 0.30 \\
\hline Watermelon & Fruit & $98 \cdot 2$ & $196 \cdot 42$ & $262 \cdot 96$ & $62 \cdot 85$ & $15 \cdot 91$ & 1.57 & 0.00 \\
\hline Yoghurt & Dairy & $87 . \overline{5}$ & 87.49 & 337.02 & $90 \cdot 11$ & 14.70 & 3.06 & $2 \cdot 10$ \\
\hline Low-fat milk & Dairy & $79 \cdot 7$ & $159 \cdot 31$ & 239.95 & $57 \cdot 35$ & 7.33 & 4.62 & 0.96 \\
\hline Rice with curry & Grain & 79.5 & 397.33 & 2234.30 & 534.01 & $100 \cdot 13$ & $10 \cdot 73$ & 10.09 \\
\hline Milk & Dairy & $32 \cdot 9$ & $65 \cdot 71$ & 164.98 & 39.43 & 3.09 & $2 \cdot 10$ & $2 \cdot 10$ \\
\hline Stir-fried dried shrimp & $\begin{array}{l}\text { Fish, } \\
\text { vegetables }\end{array}$ & $30 \cdot 0$ & 6.00 & $82 \cdot 80$ & $19 \cdot 79$ & $1 \cdot 71$ & 1.41 & 0.81 \\
\hline Steamed skate & $\begin{array}{l}\text { Fish, } \\
\text { vegetables }\end{array}$ & $27 \cdot 4$ & $125 \cdot 81$ & 595.89 & $142 \cdot 42$ & $19 \cdot 65$ & $14 \cdot 29$ & 0.30 \\
\hline Potato fries & Grain & $27 \cdot 2$ & $40 \cdot 85$ & $524 \cdot 13$ & $125 \cdot 27$ & $15 \cdot 36$ & 1.50 & 6.43 \\
\hline Roasted pork ribs & Meat & $14 \cdot 1$ & 49.51 & $556 \cdot 97$ & $133 \cdot 12$ & $4 \cdot 12$ & $10 \cdot 28$ & 8.40 \\
\hline Seasoned skate & $\begin{array}{l}\text { Fish, } \\
\quad \text { vegetables }\end{array}$ & 11.4 & 22.89 & $95 \cdot 27$ & $22 \cdot 77$ & 2.98 & 2.05 & 0.30 \\
\hline Roasted mackerel & Fish & 8.7 & $21 \cdot 85$ & $244 \cdot 18$ & $58 \cdot 39$ & 0.17 & $5 \cdot 17$ & 4.13 \\
\hline Oyster rice soup & $\begin{array}{l}\text { Grain, } \\
\text { shellfish }\end{array}$ & $2 \cdot 7$ & $17 \cdot 56$ & $77 \cdot 19$ & 18.45 & $2 \cdot 39$ & $1 \cdot 15$ & 0.48 \\
\hline Strawberry & Fruit & 1.8 & 3.58 & 4.35 & 1.04 & 0.26 & 0.03 & 0.00 \\
\hline Total & - & $901 \cdot 1$ & 1694.31 & 8158.80 & 1950.00 & $316 \cdot 88$ & 63.76 & 48.90 \\
\hline
\end{tabular}

need for consuming vitamins and minerals from additional sources for both males and females. The high usage of $\mathrm{Na}$ in Korean dine-out menus was found to be the biggest concern and this had broad effect because limiting the intake of $\mathrm{Na}$ resulted in dine-out plans with low content of minerals.
The model used in our analysis allowed investigating nutrient information in the most optimal combination among all possible combinations of dine-out menus because it was formulated as an LP problem. Formulating a diet optimization problem as a linear program is a major advantage because the problem can be efficiently solved 
Table 8 Food categories selected by dine-out menu optimization in Case D for Korean females aged 30-49 years

\begin{tabular}{|c|c|c|c|c|c|c|c|}
\hline Food group & Optimal amount (\%) & Serving size $(\mathrm{g})$ & Energy (kJ) & Energy (kcal) & Carbohydrate (g) & Protein $(\mathrm{g})$ & Total fat $(\mathrm{g})$ \\
\hline Grain & $258 \cdot 0$ & $696 \cdot 96$ & $4947 \cdot 58$ & $1182 \cdot 50$ & $216 \cdot 48$ & $16 \cdot 25$ & 27.91 \\
\hline Meat, fish, shellfish & $58 \cdot 6$ & 157.50 & $1226 \cdot 83$ & 293.22 & $17 \cdot 64$ & 24.90 & 13.47 \\
\hline Vegetables & 84.4 & $127 \cdot 35$ & $483 \cdot 21$ & 115.49 & $17 \cdot 37$ & 9.02 & 0.85 \\
\hline Fruit & $300 \cdot 0$ & $400 \cdot 00$ & $719 \cdot 19$ & $171 \cdot 89$ & $40 \cdot 27$ & 3.80 & 1.50 \\
\hline Dairy & $200 \cdot 0$ & 312.51 & 781.95 & $186 \cdot 89$ & $25 \cdot 11$ & $9 \cdot 78$ & $5 \cdot 16$ \\
\hline Total & $901 \cdot 1$ & 1694.31 & $8158 \cdot 80$ & $1950 \cdot 00$ & $316 \cdot 88$ & 63.76 & 48.90 \\
\hline
\end{tabular}

and include various restrictions on nutrients or eating habits.

Linear optimization models have been applied to nutrient analysis under various settings. Most of the studies have focused on improving one's diet in order to meet certain health goals. Soden and Fletcher ${ }^{(20)}$ formulated a linear program that computes the optimal food quantities of an observed diet and demonstrated the case for a 50-year-old overweight female with nutrient targets for energy, fibre, $\mathrm{Na}$ and fat. Masset et al. ${ }^{(21)}$ also concentrated on improving one's original diet with minimum change but they applied constraints based on guidelines for cancer prevention. The model was further explored in Okubo et al. ${ }^{(24)}$ as they designed a diet model optimized for the food intake patterns in Japan by considering twenty-eight nutrients. The case for developing countries was illustrated in Ferguson et $a l^{(22)}$, who also discussed testing the robustness of their model using a second LP model; and the nutritional quality of food aid delivered by food banks in France was analysed by Rambeloson et al. ${ }^{(25)}$. Moreover, there are studies that have incorporated cost into the model to analyse the effect of having a budget on healthy food choices ${ }^{(26,27)}$ and extensions for revising over-restricted or unrealistic diet choices using goal programming ${ }^{(28,29)}$.

The most relevant to the present study is the work by Asano $^{(30)}$ that focused on nutrient optimization in Korean meals. Asano studied the food intake patterns of Koreans and formed a healthy Korean diet based on the widely used formulation given by equation (1). As discussed in the 'Methods' section, our approach is distinct from previous studies because the goal here is not to improve an existing diet pattern but to analyse the nutritional deficiency of the most optimal choice. Furthermore, we examined a comprehensive list of dine-out menus in Korea that provide detailed information rather than observing food groups or categories.

First, we found that a healthy diet cannot be achieved with any combination among Korean dine-out menus; it is impossible to meet all recommended nutrient guidelines regardless of which combination of dine-out menus is selected. Second, our results confirmed that excessive intake of $\mathrm{Na}$ is the major concern for Korean menus. Finally, we showed that dine-out meals require additional consumption of fruits and dairy products in order to achieve a balanced diet. It is also noteworthy to mention that additional consumption of fruits and dairy products was necessary to meet daily requirements of vitamins and minerals. The addition of fruits and dairy products in optimization models to solve the deficiency of vitamins and minerals is due to the characteristics of Koreans' diet. Unlike the Western diet, the traditional Korean diet is composed of rice and various side dishes such as meat, fish, legumes and vegetables ${ }^{(31)}$, but it does not include fruits and dairy foods. Thus, people should consume those foods separately from meals as a dessert or snack in order to achieve a balanced diet. However, it is hard to eat them when eating out unless people go to a café or dessert shop because Korean restaurants usually do not provide a dessert menu with meals. Given that, it is meaningful to add fruits and dairy products, not other food groups, in dine-out menus for the optimized diet among Koreans. This result emphasizes the importance of a balance diet comprised of various food groups for nutritional adequacy. Dine-out menus lack variety because the menu is mainly single dish not like a meal at home. Therefore, the optimization proves that the additional supplements are needed to secure the balance and variety in food choice for nutritional adequacy in dining out.

The optimization formulation tested here is less restricted than real-world dine-out decisions. In reality, individuals will also take price, taste, restaurant location and time constraint into consideration when deciding where to eat out. Since our optimization problem could not find a well-balanced dine-out menu combination, this shows that excess of $\mathrm{Na}$ and deficiency of minerals are more critical and it is impossible to maintain a healthy diet from eating out in real life in South Korea.

While the less restricted analysis provides meaningful findings, we note that there are a few limitations that can be improved in future work. It will be possible to analyse more intuitive diet plans if common dining patterns were reflected in the model. For example, it is less likely that one would eat pizza with kimchi, and these could be avoided if we add constraints to the model. Moreover, current analysis found the optimal menu combination for daily consumption without making distinction among breakfast, lunch and dinner. Incorporating eating patterns will help prepare an 
optimal meal plan for a day. Nevertheless, this task requires much observation, data and careful modelling because common dining patterns do not represent everyone's eating habits. In addition, the analysis can be improved by expanding the data on dine-out menus. The analysis presented herein includes 317 dine-out items, nine fruits and five dairy products, which covers a wide range of dining options, but it will be interesting to observe the results when further extending the list of menus.

\section{Conclusion}

In conclusion, our findings revealed that it is unlikely to satisfy all nutrient recommendations with any combination of dine-out menus. Specifically, high levels of Na must be resolved with extra consumption of fruits and dairy products. Our results showed that the best meal combination, even though the proportion and pairing of menus may be unrealistic, is not healthy and thus one should not fully depend on eating out.

\section{Acknowledgements}

Financial support: This research was supported in part by the Basic Science Research Program of the National Research Foundation of Korea (NRF), funded by the Ministry of Education, Science, and Technology (grant number NRF2016R1D1A1B03931307). The NRF had no role in the study design, data analysis or writing of this article. Conflict of interest: None. Authorship: J.H.K. contributed to the acquisition of the data, the analysis and interpretation of the data and wrote the paper; W.C.K. helped with research design and interpretation of the data; J.K. contributed to research design, interpretation of the data, writing paper and had primary responsibility for the final content. All authors read and approved the final manuscript. Ethics of human subject participation: Not applicable.

\section{References}

1. Papier K, Jordan S, D'Este C et al. (2017) Social demography of transitional dietary patterns in Thailand: prospective evidence from the Thai Cohort Study. Nutrients 9, 1173 .

2. Arruda SPM, da Silva AAM, Kac G et al. (2014) Socioeconomic and demographic factors are associated with dietary patterns in a cohort of young Brazilian adults. $B M C$ Public Health 14, 654.

3. Zang J, Luo B, Wang Y et al. (2018) Eating out-of-home in adult residents in Shanghai and the nutritional differences among dining places. Nutrients 10, 951 .

4. Kwon YS \& Ju SY (2014) Trends in nutrient intakes and consumption while eating-out among Korean adults based on
Korea National Health and Nutrition Examination Survey (1998-2012) data. Nutr Res Pract 8, 670-678.

5. Kant AK \& Graubard BI (2004) Eating out in America, 1987-2000: trends and nutritional correlates. Prev Med 38, 243-249.

6. Hillier-Brown FC, Summerbell CD, Moore HJ et al. (2017) A description of interventions promoting healthier ready-toeat meals (to eat in, to take away, or to be delivered) sold by specific food outlets in England: a systematic mapping and evidence synthesis. BMC Public Health 17, 93.

7. Lachat C, Nago E, Verstraeten R et al. (2012) Eating out of home and its association with dietary intake: a systematic review of the evidence. Obes Rev 13, 329-346.

8. Watts AW, Valente M, Tu A et al. (2017) Eating away from home: influences on the dietary quality of adolescents with overweight or obesity. Can J Diet Pract Res 78, 166-171.

9. Oh C, Kim HS \& No JK (2015) Impact of dining out on nutritional intake and metabolic syndrome risk factors: data from the 2011 Korean National Health and Nutrition Examination Survey. BrJ Nutr 113, 473-478.

10. Lee KW, Song WO \& Cho MS (2016) Dietary quality differs by consumption of meals prepared at home vs. outside in Korean adults. Nutr Res Pract 10, 294-304.

11. Ministry of Food and Drug Safety (2012) 2012 Nutrient Composition Data for Dine Out Menu I. Osong: Ministry of Food and Drug Safety.

12. Ministry of Food and Drug Safety (2013) 2013 Nutrient Composition Data for Dine Out Menu II. Osong: Ministry of Food and Drug Safety.

13. Ministry of Food and Drug Safety (2015) 2015 Nutrient Composition Data for Dine Out Menu III. Osong: Ministry of Food and Drug Safety.

14. Ministry of Food and Drug Safety (2016) 2016 Nutrient Composition Data for Dine Out Menu IV. Osong: Ministry of Food and Drug Safety.

15. Korean Nutrition Society (2015) CanPro 5.0 (Web version). http://canpro5.kns.or.kr/uat/uia/canproExpertLogin.do (accessed December 2017).

16. Korean Nutrition Society (2016) 2015 Dietary Reference Intake for Koreans. Seoul: Korean Nutrition Society.

17. Gilmore A \& Redman L (2018) Calorie restriction for human aging: is there a potential benefit for cancer? Mol Cell Oncol 5, e1481811.

18. Bertsimas D \& Tsitsiklis JN (1997) Introduction to Linear Optimization. Belmont, MA: Athena Scientific.

19. Dantzig GB (2002) Linear programming. Oper Res 50 , 42-47.

20. Soden PM \& Fletcher LR (1992) Modifying diets to satisfy nutritional requirements using linear programming. $\mathrm{Br} J$ Nutr 68, 565-572.

21. Masset G, Monsivais P, Maillot M et al. (2009) Diet optimization methods can help translate dietary guidelines into a cancer prevention food plan. J Nutr 139, 1541-1548.

22. Ferguson EL, Darmon N, Briend A et al. (2004) Food-based dietary guidelines can be developed and tested using linear programming analysis. J Nutr 134, 951-957.

23. Mason AJ (2012) OpenSolver - an open source add-in to solve linear and integer progammes in Excel. In Operations Research Proceedings 2011, pp. 401-406. Berlin: Springer.

24. Okubo H, Sasaki S, Murakami K et al. (2015) Designing optimal food intake patterns to achieve nutritional goals for Japanese adults through the use of linear programming optimization models. Nutr J 14, 57.

25. Rambeloson ZJ, Darmon N \& Ferguson EL (2008) Linear programming can help identify practical solutions to improve the nutritional quality of food aid. Public Health Nutr 11, 395-404.

26. Darmon N, Ferguson EL \& Briend A (2002) A cost constraint alone has adverse effects on food selection and nutrient density: an analysis of human diets by linear programming. $J$ Nutr 132, 3764-3771. 
27. Darmon N, Ferguson EL \& Briend A (2006) Impact of a cost constraint on nutritionally adequate food choices for French women: an analysis by linear programming. J Nutr Educ Behav 38, 82-90.

28. Anderson AM \& Earle MD (1983) Diet planning in the third world by linear and goal programming. $J$ Oper Res Soc $\mathbf{3 4}$, 9-16.

29. Ferguson EL, Darmon N, Fahmida U et al. (2006) Design of optimal food-based complementary feeding recommendations and identification of key 'problem nutrients' using goal programming. J Nutr 136, $2399-2404$.

30. Asano K (2017) Development of healthy Korean meal patterns for Korean adults using linear programming. PhD Thesis, Seoul National University.

31. Lee J \& Kim J (2018) Egg consumption is associated with a lower risk of type 2 diabetes in middle-aged and older men. Nutr Res Pract 12, 396-405. 